\title{
ASSESSMENT OF SERUM LEVELS OF ANTIGLIADIN ANTIBODIES (IGG AND IGA) IN PATIENTS WITH ALOPECIA AREATA AND THEIR RELATION TO SEVERITY OF THE DISEASE
}

\author{
By \\ Alaa Makram Mohamed*, Hanan Mohamed Ali Darwish*, Hoda Kamal \\ Al-Sebaay*, and Sarah younes Abd El-Aziz** \\ *Dermatology and Venereology Department, Faculty of Medicine (Girls), Al-Azhar \\ University \\ **Clinical Pathology Department, Faculty of Medicine (Girls) Al-Azhar University \\ Corresponding Author: Alaa Makram Mohamed
}

Mobile: (+02) 01098045467, E-mail: dr.alaa.makram01@gmail.com

\begin{abstract}
Background: Alopecia areata is an autoimmune disease mediated by T-lymphocytes in which autoantigens play an important part in activating T-cells and is associated with other autoimmune diseases. Hair follicle is an immune-privileged site where major histocompatibility complex (MHC) Class I and II molecules are not expressed. Celiac disease (CD) is an autoimmune disorder that affects people who are genetically predisposed to develop an immune reaction to gluten. The small intestine is the primary site of CD. The clinical presentation, on the other hand, can be distinguished by both intestinal and extra-intestinal manifestations. Serological tests are initially recommended for the diagnosis of $\mathrm{CD}$. One of the most sensitive and specific tests is anti-tissue transglutaminase IgA. Other serological tests include anti-gliadin $\operatorname{IgA}$ and $\mathrm{IgG}$.

Aim of the Work: To evaluate serum level of antigliadin antibodies (Ig A and Ig G classes) in patients with alopecia areata and their relation to the severity of the disease.

Patients and Methods: This case control study included 60 participants including 30 patients with alopecia areata and 30 healthy individuals as controls. Patients were selected from Dermatology outpatient clinic in AL Zahraa University hospital during the period from November 2020 to April 2021.

Results: Out of 30 patients with alopecia areata included in the study the severity of alopecia tool score (SALT) was S5 in 8 patients (26.7\%), S4 in $2(6.7 \%), \mathrm{S} 3$ in $1(3.3 \%), \mathrm{S} 2$ in $5(16.7 \%)$ and S1 in 14 patients $(46.7 \%)$. Antigliadin IgA was only positive in $8(26.7 \%) \mathrm{S} 5$ patients while IgG was positive in all 30 patients with 2 positive cases in control group resembling $(6.7 \%)$. There was statistically significant difference between control and patients groups regarding $\operatorname{IgA}$ and $\operatorname{IgG}$ levels, as higher values was found in patients than controls, the median (IQR) of IgA in patients was $9.11(6.88-12.2)$ while in control group was 1.56 $(0.97-3.29)$ with p-value $<0.001$. By ROC curve for sensitivity and specificity of IgA and IgG, we found that there were $100 \%$ sensitivity and specificity of IgA with cutoff point $>4.25$ and also for IgG with cutoff point $>13$.

Conclusion: There was a high statistically significant association between antigliadin antibodies $(\operatorname{IgA}$ and IgG class), and AA and its severity, with $100 \%$ sensitivity and specificity of IgA with cutoff point $>11.56$ and also for IgG with cutoff point $>41.8$. An active search for $C D$ using serological screening tests has been recommended to diagnose the numerous cases of subclinical CD in AA patients
\end{abstract}

Keywords: antigliadin antibodies, (IgG and IgA), alopecia areata. 


\section{INTRODUCTION}

Alopecia areata (AA) is a common form of immune-mediated alopecia in which an autoimmune attack on the proximal hair follicle results in nonscarring hair loss ranging in presentation from circular patches on the scalp to total scalp or full body hair loss (Putterman et al., 2019).

Alopecia areata typically begins as a small, well-demarcated patch of hair loss on the scalp or beard that may spontaneously resolve without treatment. In about $30 \%$ of cases, the disease relapses; in some cases, hair loss may progress and affects the entire scalp (alopecia totalis) or the entire body (alopecia universalis) (Breitkopf et al., 2013).

Studies suggest that alopecia areata prevalence in the USA has remained reasonably constant over the past 50 years. It is similar to the upper limit estimates in the 1970s at approximately $0.21 \%$ and with "moderate to severe" disease estimated at $0.09 \%$ and possible lifetime prevalence as high as $2.51 \%$ (Benigno et al., 2020).

Reports showed that there is no gender predominance in alopecia areata, it is considered as a disease of all age groups; however, most patients present at age of 21-40 years (Alshahrani et al., 2020).

In some studies, alopecia areata is reported accompanied with other autoimmune illnesses such as Hashimoto's thyroiditis, vitiligo, diabetes, lichen planus, and also in a few reports, celiac disease (CD) (gluten-sensitive enteropathy) (El Gayyar et al., 2011).
Celiac disease (CD) is a chronic autoimmune systemic disease associated with an enteropathy triggered by gluten intake which affects genetically predisposed individuals of both sexes and can develop at any age. Gluten and its major protein fractions, gliadin and glutenin, are present in wheat, rye, barley, oats, related species and hybrids, and processed foods (Bai et al., 2013).

Celiac disease patients are more frequently affected by other immunemediated disorders (ID) compared to the general population, as reported in previous studies, mainly thyroid and skin diseases. This observation may be partially explained by a possible spread of the adaptive immune response, initially triggered in the gastrointestinal tract, to other tissues. Hashimoto ${ }^{\text {ee }} \mathrm{s}$ thyroiditis is the most frequently associated ID, followed by several skin disorders, such as psoriasis, atopic dermatitis (AD), vitiligo, systemic lupus erythematosus (SLE), alopecia areata (AA), and oral lichen planus (OLP) (Elli et al., 2012).

Increased prevalence of serum markers for celiac disease has been reported among patients with skin disorders like psoriasis (Kolchak, et al., 2018).

The finding that intestinal intraepithelial cytotoxic CD8 Tlymphocytes (IE-CTLs) can kill epithelial cell, based on recognition of inflammatory and stress signals provides an explanation of how IECTL, without being gluten specific, can play a major role in celiac disease pathogenesis and in particular in epithelial cell destruction (Jabri and Abadie, 2015).

Substantial progress in basic and clinical immunology research suggests 
areata and its clinical variants such as patchy, ophiasis, totalis, universalis, dermoscopic examination using noncontact polarized dermoscopy (DermLite HUD dermoscope, 3Gen, USA) connected to samsung galaxy S9 plus dual lens 12 mega pixels digital camera (model SMG965F/DS). Dermoscopic examination was used to diagnose AA according to the criteria defined by Mane et al. (2011).

Clinical assessment of the degree of AA the extent of scalp hair loss was determined according to the severity of alopecia SALT scores (Olsen, 2011).

Laboratory investigations: Collection of blood samples: Three $\mathrm{ml}$ of venous blood were withdrawn from each subject. The blood were collected in plain tubes and left at room temperature to clot. Serum was separated by centrifugation for 10 $\min$ at $1500 \mathrm{rpm}$. Serum was put in Eppendorf tube for antigliadin antibodies (IgA and $\operatorname{IgG}$ ) assay. Eppendorf tubes were stored at $-20^{\circ} \mathrm{C}$ till time of assay. Assessment of serum antigliadin antibodies ( $\operatorname{Ig} \mathrm{A}$ and $\operatorname{IgG}$ ): Antigliadin antibodies ( $\operatorname{Ig} \mathrm{A}$ and $\operatorname{IgG}$ ) were assessed quantitatively in patients and controls by ELISA method with kits (ORG 534A and ORG 534G respectively, ORGENTEC
Diagnostica GmbH, Mainz, Germany) and

Positivity for both was considered $\geq 12$ $\mathrm{U} / \mathrm{ml}$ as provided by the manufacturer.

Statistical Analysis: Data were collected, revised, coded and entered to the Statistical Package for the Social Sciences (IBM SPSS) version 23. The quantitative data were presented as mean, standard deviations and ranges when parametric and median, inter-quartile range (IQR) when data found non-parametric. Also qualitative variables were presented as number and percentages.

The comparison between groups regarding qualitative data was done by using Fisher exact test. The comparison between two groups regarding quantitative data was done by using Mann-Whitney test. Receiver operating characteristic curve (ROC) was used to assess the best cut off point with its sensitivity, specificity, positive predictive value, negative predictive value and area under curve (AUC) of the studied marker.

The confidence interval was set to $95 \%$ and the margin of error accepted was set to $5 \%$. So, the p-value was considered significant as the following $\leq 0.05$. 


\section{RESULTS}

Patients were $13(43.3 \%)$ males and 17 $(56.7 \%)$ females .Their ages ranged from $2-47$ years $($ Median $(\mathrm{IQR})=17(7-33)$ Y). Among those 30 patients; 17 (56.7\%) were students, 5 patients $(16.7 \%)$ were manual workers, 3 (10.0\%) were employees, $4(13.3 \%)$ were house wifes and $1(3.3 \%)$ was nurse. 27 patients were smokers representing $(90.0 \%)$.
As regard past history of studied patients, 4 patients $(13.3 \%)$ had positive medical history and 26 patients $(86.7 \%)$ had negative medical history. Only 2 patients $(6.7 \%)$ had positive family history of AA, and 2 patients $(6.7 \%)$ had history of associated diseases (Table 1).

Table (1): Descriptive for demographic data of the studied patients

\begin{tabular}{|c|c|c|}
\hline \multicolumn{2}{|c|}{ Patient's Groups } & No. $=\mathbf{3 0}$ \\
\hline \multirow{2}{*}{ Age } & Median (IQR) & $17(7-33)$ \\
\cline { 2 - 3 } Sex & Range & $2-47$ \\
\hline \multirow{4}{*}{ Occupation } & Female & $17(56.7 \%)$ \\
\cline { 2 - 3 } & Male & $13(43.3 \%)$ \\
\cline { 2 - 3 } & Student & $17(56.7 \%)$ \\
\cline { 2 - 3 } & Employee & $3(10.0 \%)$ \\
\cline { 2 - 3 } & Worker & $5(16.7 \%)$ \\
\cline { 2 - 3 } & Housewife & $4(13.3 \%)$ \\
\hline \multirow{3}{*}{ Smoking } & Nurse & $1(3.3 \%)$ \\
\cline { 2 - 3 } & Negative & $27(90.0 \%)$ \\
\hline \multirow{2}{*}{ Medical history } & Positive & $3(10.0 \%)$ \\
\cline { 2 - 3 } & Negative & $26(86.7 \%)$ \\
\hline \multirow{2}{*}{ Family history } & Positive & $4(13.3 \%)$ \\
\hline \multirow{2}{*}{ Associated diseases } & Negative & $28(93.3 \%)$ \\
\cline { 2 - 3 } & Positive & $2(6.7 \%)$ \\
\cline { 2 - 3 } & Negative & $28(93.3 \%)$ \\
\hline
\end{tabular}

There were 6 patients $(20.0 \%)$ of alopecia areata universalis, 2 patients $(6.7 \%)$ of alopecia areata totalis, 6 patients with diffuse AA $(20.0 \%)$ and 16 patients $(53.3 \%)$ of localized AA. The onset of AA was acute in 25 patients $(83.3 \%)$, sudden in 3 patients $(10.0 \%)$ and gradual in 2 patients $(6.7 \%)$. The course was progressive in 16 patients $(53.3 \%)$, stationary in 10 patients $(33.3 \%)$ and remittent in 4 patients $(13.3 \%)$. The duration of the disease ranged between 0.1 - 50 months with Median (IQR) 5 (3 - 18) months.

As regard nail changes 18 patients had nail changes $(60.0 \%), 8$ had longitudinal ridges $(26.7 \%), 3$ had pitting and longitudinal ridges $(10.0 \%)$ and 1 had pitting (3.3\%) (Table 2). 
ALAA MAKRAM MOHAMED et al.,

Table (2): Descriptive for onset, coarse, duration, nail changes and SALT score for the studied patients

\begin{tabular}{|c|c|c|}
\hline \multicolumn{2}{|c|}{ Patient's Groups } & No. $=30$ \\
\hline \multirow{3}{*}{ Onset } & Acute & $25(83.3 \%)$ \\
\hline & Sudden & $3(10.0 \%)$ \\
\hline & Gradual & $2(6.7 \%)$ \\
\hline \multirow{3}{*}{ Coarse } & Progressive & $16(53.3 \%)$ \\
\hline & Stationary & $10(33.3 \%)$ \\
\hline & R\&E & $4(13.3 \%)$ \\
\hline \multirow{2}{*}{ Duration in months } & Median (IQR) & $5(3-18)$ \\
\hline & Range & $0.1-50$ \\
\hline \multirow{4}{*}{ Pattern of AA } & Universalis & $6(20.0 \%)$ \\
\hline & Diffuse & $6(20.0 \%)$ \\
\hline & Localized & $16(53.3 \%)$ \\
\hline & Totalis & $2(6.7 \%)$ \\
\hline \multirow{4}{*}{ Nail changes } & NAD & $18(60.0 \%)$ \\
\hline & LR & $8(26.7 \%)$ \\
\hline & Pitting & $1(3.3 \%)$ \\
\hline & LR \& pitting & $3(10.0 \%)$ \\
\hline \multirow{5}{*}{ SALT } & S1 & $14(46.7 \%)$ \\
\hline & S2 & $5(16.7 \%)$ \\
\hline & S3 & $1(3.3 \%)$ \\
\hline & S4 & $2(6.7 \%)$ \\
\hline & S5 & $8(26.7 \%)$ \\
\hline
\end{tabular}

There was a statistically significant difference between control and patients group regarding $\operatorname{IgA}$ and $\mathrm{IgG}$ levels higher in patients than control. The median (IQR) in patients was $9.11(6.88-12.2)$, while in control group was $1.56(0.97-3.29)$ with p-value $<0.001$.

There was a statistically significant difference between the two groups according to positivity of $\operatorname{IgA}$, with 8 positive cases in patients group $(26.7 \%)$, there was a statistically significant difference according to $\mathrm{IgG}$ positivity with 30 positive in patients group $(100.0 \%)$ and 2 positive cases in control group $(6.7 \%)$ with p-value $<0.001$ (Table 3).

Table (3): Comparison between control and patients groups according to Ig A and Ig $G$ levels and positivity

\begin{tabular}{|c|c|c|c|c|}
\hline \multirow{2}{*}{\multicolumn{2}{|c|}{ Parameters $\quad$ Groups }} & Patients group & Control group & \multirow{2}{*}{ P-value } \\
\hline & & No. $=30$ & No. $=30$ & \\
\hline \multirow{2}{*}{$\operatorname{IgA}(\mathrm{U} / \mathrm{ml})$} & Median (IQR) & $9.11(6.88-12.2)$ & $1.56(0.97-3.29)$ & \multirow{2}{*}{$<0.00$} \\
\hline & Range & $4.96-31.8$ & $0.16-4.25$ & \\
\hline $\begin{array}{l}\operatorname{IgA}(\mathrm{U} / \mathrm{ml}) \\
\text { positivity }\end{array}$ & $\begin{array}{l}\text { Negative } \\
\text { Positive }\end{array}$ & $\begin{array}{l}22(73.3 \%) \\
8(26.7 \%)\end{array}$ & $\begin{array}{c}30(100.0 \%) \\
0(0.0 \%)\end{array}$ & 0.005 \\
\hline \multirow{2}{*}{$\operatorname{IgG}(\mathrm{U} / \mathrm{ml})$} & Median (IQR) & $28.45(22.9-43.4)$ & $6(3.06-8.53)$ & \multirow{2}{*}{$<0.00$} \\
\hline & Range & $14.8-88.9$ & $0.79-13$ & \\
\hline $\begin{array}{l}\mathrm{IgG}(\mathrm{U} / \mathrm{ml}) \\
\text { positivity }\end{array}$ & $\begin{array}{l}\text { Negative } \\
\text { Positive }\end{array}$ & $\begin{array}{c}0(0.0 \%) \\
30(100.0 \%)\end{array}$ & $\begin{array}{c}28(93.3 \%) \\
2(6.7 \%)\end{array}$ & 0.00 \\
\hline
\end{tabular}

F: Fisher's Exact test; $\neq$ : Mann-Whitney test 
According to ROC curve, there were cutoff point $>4.25$, and also for $\operatorname{IgG}$ with $100 \%$ sensitivity and specifity of IgA with cutoff point $>13$ (Table 4 ).

Table (4): sensitivity and specifity of IgA andIgG

\begin{tabular}{|c|c|c|c|c|c|c|}
\hline Variables & Cut off point & AUC & Sensitivity & Specificity & +PV & -PV \\
\hline $\mathrm{IgA}(\mathrm{U} / \mathrm{ml})$ & $>4.25$ & 1.000 & 100.00 & 100.00 & 100.0 & 100.0 \\
\hline $\mathrm{IgG}(\mathrm{U} / \mathrm{ml})$ & $>13$ & 1.000 & 100.00 & 100.00 & 100.0 & 100.0 \\
\hline
\end{tabular}

There was a statistically significant difference between the two groups of
SALT score and IgA, IgG levels with Pvalue $<0.01$ (Table 5)

Table (5): Relation between SALT score and IgA, IgG levels

\begin{tabular}{|c|c|c|c|c|c|c|}
\hline \multirow{3}{*}{\multicolumn{2}{|c|}{ SALT Score }} & Mild to moderateS1-4 & Severe S5 & \multirow{3}{*}{ Test value } & \multirow{3}{*}{ P-value } & \multirow{3}{*}{ Sig. } \\
\hline & & No. $=22$ & No. $=8$ & & & \\
\hline & & Median (IQR) & $7.9(6.3-9.96)$ & & & \\
\hline \multirow{2}{*}{$\operatorname{IgA}(\mathbf{U} / \mathbf{m l})$} & Range & $4.96-11.56$ & $20.05(15.95-25.65)$ & \multirow{2}{*}{$-4.127 \neq$} & \multirow{2}{*}{0.000} & \multirow{2}{*}{ HS } \\
\hline & Median (IQR) & $25.55(19.4-29.88)$ & $12.2-31.8$ & & & \\
\hline \multirow{2}{*}{$\operatorname{IgG}(\mathrm{U} / \mathrm{ml})$} & Range & $14.8-41.8$ & $61.3(47.4-73.45)$ & \multirow{2}{*}{$-4.127 \neq$} & \multirow{2}{*}{0.000} & \multirow{2}{*}{ HS } \\
\hline & Range & & & & & \\
\hline
\end{tabular}

\#: Mann-Whitney test

\section{DISCUSSION}

For the diagnosis of $\mathrm{CD}$, initially, serological tests are recommended. Antitissue transglutaminase $\operatorname{Ig} \mathrm{A}$ is one of the most sensitive and specific tests. Antigliadin $\operatorname{IgA}$ and $\operatorname{IgG}$ are other serological tests (Tonutti and Bizzaro, 2014).

In the last years, skin diseases as alopecia areata are acquiring more and more importance among the extraintestinal manifestations of CD (Hujoel et al., 2019).

In this study, we aimed to evaluate serum level of antigliadin antibodies (Ig A and Ig $\mathrm{G}$ class) in patients with alopecia areata and its relation to the severity of the disease.

We enrolled 60 subjects and divided them into 2 groups: Group 1: Included 30 apparently healthy individuals as a control group and Group 2: Included 30 patients with alopecia areata.
Alopecia areata can occur at any age and the lifetime incidence appears to increase at an almost linear rate. The median age at diagnosis is 33 . Mirzoyev et al. (2014) in the current study the age ranged from $2-47$ years with Median $(\mathrm{IQR})=17(7-33) \mathrm{Y})$.

In line with Gilhar et al. (2012) more than $66 \%$ of the patients were younger than 30 years old and only $20 \%$ were over 40 years old. Salo-Mullen et al. (2015) mentioned that up to $85.5 \%$ of patients' experience disease onset before the age of 40 years. Late-onset AA is relatively rare. It can be explained through the fact that children's clinics were separated from adult's clinics. In this study $56.7 \%$ of AA patients were females and $43.3 \%$ were males.

Studies with regard to gender predominance in AA are conflicting. A systematic review concluded that there is 
no difference in the incidence of AA between males and females (Villasante and Miteva, 2015), and no sex predilection for AA was found by Bhat et al. (2017) where the represented some studies showed male preponderance as Tonutti and Bizzaro (2014) 58.8\%, and Ragab et al. (2020) showed that $\{65 \%\}$ were males.

Other studies showed female predominance as ours, and Lundin et al, (2014) explained that it may be due to higher female concern regarding hair loss and subsequent treatment, and Male patients may be more likely to be diagnosed in childhood, while females are more likely to present in adolescents.

AA has three main variants which are patchy AA (localized hairless areas), alopecia totalis (entire scalp affected), and alopecia universalis affecting all body surface area (Jabbari et al., 2016). In the current study, $53.3 \%$ of patients had localized AA, followed by AAU and diffuse AA each of them represent $20 \%$ and $6.7 \%$ ) had AAT

Other studies found that the patchy scalp being the most predominant type in Hallaji et al. (2011), Mulders et al. (2011), and Fricke \& Miteva (2015).

Tonutti and Bizzaro (2014) found that the most frequent type of AA was patchy $(88.6 \%)$. The second frequent form was totalis $(6.8 \%)$.

Nail involvement has been reported from $7 \%$ to $66 \%$, with an average prevalence of approximately $30 \%$, and is observed more frequently in children $(>40 \%)$ than in adults $(<20 \%)$, and more frequently in severe disease. It consists of nail pitting, trachyonychia. Less frequent nail changes are punctate leukonychia, spotted or red lunulae, Beau's lines and very rarely onychomadesis (Chelidze and Lipner, 2018).

As regard nail changes in this study, $60.0 \%$ patients had no nail changes, $26.7 \%$ had longitudinal ridges $10.0 \%$ had pitting and3.3\% had both pitting and longitudinal ridges. While concerning the nail involvement, by Tonutti and Bizzaro (2014) where $88.5 \%$ of the patients had no involvement, but $5.7 \%, 2.9 \%$, and $2.9 \%$ of them had pitting, ridging, and onycholysis, respectively.

On other hand, nail affection was not detected in association with alopecia areata patients by Ragab et al. (2020).

The discrepancy may be contributed to difference in participant's characters as onset, severity and course of the disease.

In the present study, only $6.7 \%$ had positive family history of AA. Which was In line with Mulders et al. (2011) who found positive family history of AA was positive in $6 \%$ of patients, and $\mathrm{El} \mathrm{Aziz}$ Ragab et al. (2020) whereas a positive family history of alopecia areata in firstdegree relatives was detected in $(5 \%)$ patients.

Also, Tonutti and Bizzaro (2014) concluded that most of the participants in the case group did not have any positive familial history of AA (82.9\%).

Other previous studies have shown that $3 \%-42 \%$ of AA patients report a family history of the disease, with a greater prevalence in those with early-onset and very low or no prevalence in those with late-onset AA (Wu et al., 2013; Lee et al., 2014; Jang et al., 2015 and Lyakhovitsky et al., 2017). 
There was 2 patients representing $(6.7 \%)$ in our study had history of associated diseases.

The association of AA with other autoimmune disease had variable results in the literature. Some studies showed that AA is not related to other autoimmune diseases (Alkhalifah et al., 2010). However, many other studies demonstrated that AA is associated with several autoimmune diseases (Abd ElMawla \& Maghrabi, 2015; and Dainichi \& Kabashima, 2017).

Mulders et al. (2011) stated that the 3 most commonly reported comorbidities were hypothyroidism, asthma, anid diabetes mellitus. The association between AA and other diseases may contribute to a same auto immune background of both diseases.

In our study; the extent of the scalp involvement was evaluated using the Severity Alopecia Tool (SALT), as follows: S1 (<25\% scalp involvement), S2 (26\% 50\%), S3 (51\% 75\%), S4 (76\% 99\%), and S5 (100\%, alopecia totalis)and we found $46 \%$ were S1, $26.7 \%$ were S2, $16.7 \%$, followed by $S 4(6.7 \%)$ and S3(3.3\%), with statistically significant difference between SALT score and the duration of the disease, and nonsignificant difference was found regarding other parameters as age or sex You and Kim (2017) found a statistically significant difference with duration of the disease as higher duration related with sever disease. Both in the AA and in the $\mathrm{CD}$, the presence of organ-specific autoantibodies has been demonstrated, with infiltration of $\mathrm{T}$ lymphocytes on the lesion site (Pratt et al., 2017).
There have been other reports of this novel association. The study by Ertekin et al. (2014) found that the prevalence of CD in children with AA was $41.7 \%$ while in healthy children in the same city was $0.87 \%$. This indicated that the prevalence of silent $\mathrm{CD}$ was very high among children with AA. Hence, it can be said that AA could be the only clinical manifestation of $\mathrm{CD}$ in some cases (Ertekin et al., 2014).

A few case reports proposed an association between $\mathrm{CD}$ and $\mathrm{AA}$. In a prospective trial of 256 AA patients, 6 had positive tissue transglutaminase and endomysial with positive biopsy (Denham and Hill, 2013). In another study, Hallaji et al. (2011) estimated the prevalence of anti-gliadin antibodies in patients with AA to be about 18\% (Hallaji et al., 2011).

In the current study, there was statistically significant difference between control and patients group regarding IgA and $\mathrm{IgG}$ levels, as higher values was found in patients than control, the median (IQR) of Ig A in patients was 9.11 (6.88 12.2) while in control group was 1.56 $(0.97-3.29$ with p-value $<0.001$. With 8 positive cases in patients group representing $(26.7 \%)$, and according to IgG positivity with 30 positive in patients group resembling (100.0\%) and 2 positive cases in control group resembling $(6.7 \%)$

On other side, results of Tonutti and Bizzaro (2014) showed that in their population, there was no significant difference between the two groups in terms of celiac autoantibodies (antigliadin IgA, anti-gliadin IgG, and antitissue transglutaminase $\operatorname{IgA}$ ), which could be due to different demographic compositions. 
In our study, we used ROC curve for sensitivity and specificity of $\operatorname{IgA}$ and $\operatorname{IgG}$ and found that there were $100 \%$ sensitivity and specificity of $\operatorname{IgA}$ with cutoff point $>4.25$ and also for IgG with cutoff point $>13$. Also ROC curve for $\operatorname{Ig} \mathrm{A}$ and $\operatorname{IgG}$ was used to predict the class of SALT score and we found that there were $100 \%$ sensitivity and specificity of $\operatorname{IgA}$ with cutoff point $>11.56$ and also for IgG with cutoff point $>41.8$.

Regarding severity score, there was statistically significant difference between SALT score, pattern, and course of alopecia areata and also with $\operatorname{IgA}$ and $\operatorname{IgG}$ levels. As higher values found in higher severity score. Also we found a positive correlation between IgA and IgG with the duration.

In a recent case reported by Aggarwal et al. (2020), they found an association in a 41/2-year-old boy, who was referred by a dermatologist for gastrointestinal (GI) symptoms, as his complaint with loss of hair on the anterior half of his scalp for the past 8 months without any improvement. A diagnosis of $\mathrm{CD}$ was confirmed by duodenal biopsy and serology for antiendomysial and antigliadin antibodies. And treated with gluten-free diet (GFD), after 6 months later according to his parents, hair regrowth started once his GI symptoms subsided after the initiation of GFD.

Although remission and recurrence may be observed during the clinical course of AA, many patients on GFD have shown complete regrowth of hair with no further recurrence of AA at follow-up, these positive effects of GFD have been attributed to the normalization of the immune response (Rodrigo et al., 2018).
All these finding detect high association between antigliadin antibodies (Ig A and Ig G class), CD and AA and its severity that needed further studies in multicenter.

\section{CONCLUSION}

There was a statistically significant association between antigliadin antibodies (Ig A and Ig G class), and AA and its severity, with $100 \%$ sensitivity and specificity of IgA with cutoff point $>11.56$ and also for IgG with cutoff point $>41.8$. An active search for $C D$ using serological screening tests has been recommended to diagnose the numerous cases of subclinical CD in AA patients

\section{REFERENCES}

1. Abd El-Mawla AM and Maghrabi IA (2015): Prevalence and treatment of Alopecia areata in Taif area, KSA. Saudi J Health Sci.4:125-8.

2. Aggarwal S, Aggarwal $S$ and Kalra RK (2020): Underlying celiac disease in children with alopecia areata: An association. Indian Journal of Paediatric Dermatology, 21(1): 77-82.

3. Alkhalifah A, Alsantali A, Wang E, McElwee KJ and Shapiro J (2010): Alopecia areata update: part I. Clinical picture, histopathology, and pathogenesis. Journal of the American Academy of Dermatology, 62(2): 177-188.

4. Alshahrani, A. A., Al-Tuwaijri, R., Abuoliat, Z. A., Alyabsi, M., AlJasser, M. I., and Alkhodair, R. (2020): Prevalence and clinical characteristics of alopecia areata at a tertiary care center in Saudi Arabia. Dermatology research and practice, 2020 Mar 13; 2020.

5. Bai JC, Fried M, Corazza GR, Schuppan D, Farthing M, Catassi C and LeMair A (2013): World 
Gastroenterology Organisation global guidelines on celiac disease. Journal of Clinical Gastroenterology, 47(2): 121126.

6. Benigno $\mathrm{M}$, Anastassopoulos KP, Mostaghimi A, Udall M, Daniel SR, Cappelleri JC, Chander P, Wahl PM, Lapthorn J, Kauffman $L$ and Chen $L$ (2020): A large cross-sectional survey study of the prevalence of alopecia areata in the United States. Clinical, Cosmetic and Investigational Dermatology, 13:259265.

7. Bhat YJ, Latif I, Malik R, Hassan I, Sheikh G, Lone KS, Majeed S and Sajad P (2017): Vitamin D level in alopecia areata. Indian Journal of Dermatology, 62(4):407- 412.

8. Breitkopf T, Leung G, Yu M, Wang E and McElwee KJ (2013): The basic science of hair biology: what are the causal mechanisms for the disordered hair follicle?. Dermatologic Clinics. 31(1):1-9.

9. Brusca, I. (2015): Overview of biomarkers for diagnosis and monitoring of celiac disease. Advances in Clinical Chemistry, 68: 1-55.

10. Chelidze $K$ and Lipner SR (2018): Nail changes in alopecia areata: an update and review. International Journal of Dermatology, 7(57): 776-783.

11. Dainichi $T$ and Kabashima $K$ (2017): Alopecia areata: what's new in epidemiology, pathogenesis, diagnosis, and therapeutic options? Journal of Dermatological Science, 86: 3-12.

12. Denham JM and Hill ID (2013): Celiac disease and autoimmunity: review and controversies. Curr Allergy Asthma Rep., 4(13): 347-53.

13. El Gayyar MA, Helmy MI, Abdelhafez A, Omran NA and Amer ER (2011): Evaluation of thyroid hormone abnormalities and thyroid autoantibodies in chronic idiopathic urticaria and alopecia areata Egyptian patients. Asian J Dermatol., 3(1):1-2.

14. Elli L, Bonura A, Garavaglia D, Rulli E, Floriani I, Tagliabue G, Contiero P and Bardella MT (2012): Immunological comorbity in coeliac disease: associations, risk factors and clinical implications. Journal of Clinical Immunology, 32(5):984-90.

15. Ertekin V, Tosun MS and Erdem $T$ (2014): Screening of celiac disease in children with alopecia areata. Indian $\mathrm{J}$ Dermatol., 3(59): 317.

16. Fricke ACV and Miteva M (2015): Epidemiology and burden of alopecia areata: a systematic review. Clinical, Cosmetic and Investigational Dermatology, (8): 397.

17. Gilhar A, Etzioni A and Paus R (2012): Alopecia areata. New England Journal of Medicine. 366(16):1515-25.

18. Hallaji Z, Akhyani M, Ehsani AH, Noormohammadpour P, Gholamali F, Bagheri $M$ and Jahromi J (2011): Prevalence of anti-gliadin antibody in patients with alopecia areata: a casecontrol study. Tehran University Medical Journal., 68(12): 762-769.

19. Hujoel IA, Reilly NR and Rubio-Tapia A (2019): Celiac disease: clinical features and diagnosis. Gastroenterology Clinics, 48: 19-37.

20. Jabbari A, Cerise JE, Chen JC, Mackay-Wiggan J, Duvic M, Price V, Hordinsky M, Norris D, Clynes $R$ and Christiano AM (2016): Molecular signatures define alopecia areata subtypes and transcriptional biomarkers. $\mathrm{E}$ BioMedicine, 7:240-7.

21. Jabri B and Abadie V (2015): IL-15 functions as a danger signal to regulate tissue-resident $\mathrm{T}$ cells and tissue 
destruction. Nat Rev Immunol. 15(12):771-83.

22. Jang YH, Park KH, Kim SL, Lim HJ, Lee WJ and Lee SJ (2015): Alopecia areata in the elderly: a 10-year retrospective study. Annals of Dermatology, 27(4):411-6.

23. Karnsakul W, Skitarelic K, Gillespie S and Arkachaisri $T$ (2012): Isolated positive anti-gliadin immunoglobin-A antibody in children with gastrointestinal symptoms. Turk J Gastroenterol., 23(5):485-9.

24. Kinori M, Kloepper JE and Paus $R$ (2011): Can the hair follicle become a model for studying selected aspects of human ocular immune privilege? Investigative Ophthalmology \& Visual Science, 52(7):4447-58.

25. Lee NR, Kim BK, Yoon NY, Lee SY, Ahn SY and Lee WS (2014): Differences in comorbidity profiles between earlyonset and late-onset alopecia areata patients: a retrospective study of 871 Korean patients. Annals of Dermatology, 26(6):722-6.

26. Lundin M, Chawa S, Sachdev A, Bhanusali $D$, Seiffert-Sinha $K$ and Sinha AA (2014): Gender differences in alopecia areata. Journal of Drugs in Dermatology: JDD, 13(4):409-13.

27. Lyakhovitsky A, Gilboa S, Eshkol A, Barzilai $A$ and Baum $S$ (2017): Lateonset alopecia areata: a retrospective cohort study. Dermatology. 233(4):28994.

28. McElwee KJ, Gilhar A, Tobin DJ, Ramot Y, Sundberg JP, Nakamura M, Bertolini M, Inui S, Tokura Y, King LE and Duque-Estrada B (2013): What causes alopecia areata? Section Editors: Ralf Paus, Manchester/Lübeck and Raymond Cho, San Francisco. Experimental Dermatology, 22(9):609-26.
29. Mirzoyev SA, Schrum AG, Davis MD and Torgerson RR (2014): Lifetime incidence risk of Alopecia Areata estimated at 2.1 percent by Rochester Epidemiology Project, 1990-2009. The Journal of Investigative Dermatology. 134(4):1141-1147.

30. Mokhtari, A., and Ribeiro, A. (2016): DSA: Decentralized double stochastic averaging gradient algorithm. The Journal of Machine Learning Research, 17(1), 2165-2199.

31. Mulders, T. A., Meyer, Z., Van der Donk, C., Kroon, A. A., Ferreira, I., Stehouwer, C. D., \& Pinto-Sietsma, S. J. (2011): Patients with premature cardiovascular disease and a positive family history for cardiovascular disease are prone to recurrent events. International journal of cardiology, 153(1), 64-67.

32. Olsen EA (2011): Investigative guidelines for alopecia areata. Dermatol Ther., 24:311-319.

33. Pratt CH, King LE, Messenger AG, Christiano AM and Sundberg JP (2017): Alopecia areata. Nature reviews Disease Primers. 3(1):1-7.

34. Putterman E, Patel DP, Andrade G, Harfmann KL, Hogeling M, Cheng CE, Goh C, Rogers RS and Castelo-Soccio L (2019): Severity of disease and quality of life in parents of children with alopecia areata, totalis, and universalis: a prospective, cross-sectional study. Journal of the American Academy of Dermatology, 80(5):1389-94.

35. Ragab MA, Hassan EM, El Niely DA and Mohamed MM (2020): Serum level of interleukin-15 in active alopecia areata patients and its relation to age, sex, and disease severity. Advances in Dermatology and Allergology/Postępy Dermatologii i Alergologii. 37(6):904911. 
36. Rodrigo L, Beteta-Gorriti V, Alvarez $\mathrm{N}$, Gómez de Castro C, De Dios A, Palacios L and Santos-Juanes J (2018): Cutaneous and mucosal manifestations associated with celiac disease. Nutrients, 10(7):800-806.

37. Rubio-Tapia A, Hill ID, Kelly CP, Calderwood AH and Murray JA (2013): American College of Gastroenterology clinical guideline: diagnosis and management of celiac disease. The American Journal of Gastroenterology, 108(5):656-661.

38. Salo-Mullen, E. E., O'Reilly, E. M., Kelsen, D. P., Ashraf, A. M., Lowery, M. A., Yu, K. H., ... and Stadler, Z. K. (2015): Identification of germline genetic mutations in patients with pancreatic cancer. Cancer, 121(24), 43824388 .

39. Tedeschi, S. K., Bermas, B., \& Costenbader, K. H. (2013): Sexual disparities in the incidence and course of SLE and RA. Clinical Immunology, 149(2), 211-218.
40. Tonutti, E., \& Bizzaro, N. (2014): Diagnosis and classification of celiac disease and gluten sensitivity. Autoimmunity reviews, 13(4-5), 472-476.

41. Villasante AC and Miteva M (2015): Epidemiology and burden of alopecia areata: a systematic review. Clin Cosmet Investig Dermatol., (8):397-403.

42. Wu MC, Yang CC, Tsai RY and Chen WC (2013): Late-onset areata: a retrospective study of 73 patients from Taiwan. Journal of the European Academy of Dermatology and Venereology, 27(4):468-72.

43. You HR and Kim SJ (2017): Factors Associated with Severity of Alopecia Areata. Annals of Dermatology, 5(29), 565-570. 


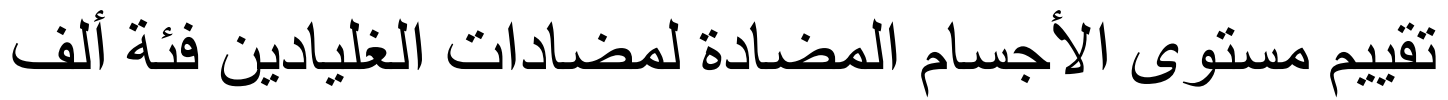 وجيم في سبرم مر ضي الثعلبة البقعية و علاقتها بدرجة شدة

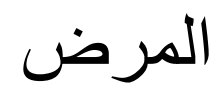

ألاء مكرم محمود عبد الوهاب*، حنان محمد على درويش*، هـدى كمال السباعى*،

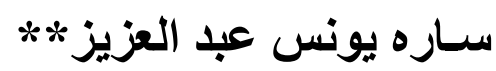

*قسم الأمراض الجلاية والتناسلية، كلية طب بنات، جامعة الأزهر

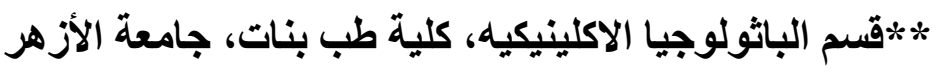

E-mail: dr.alaa.makram01@gmail.com

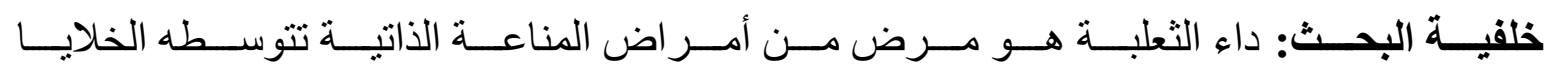

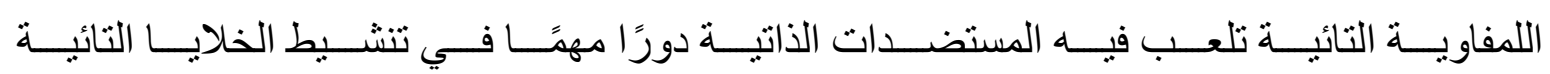

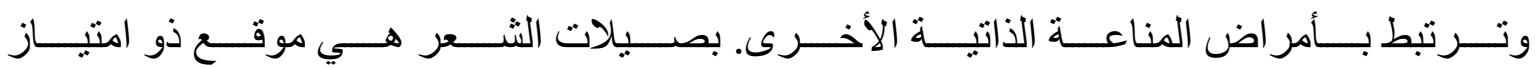

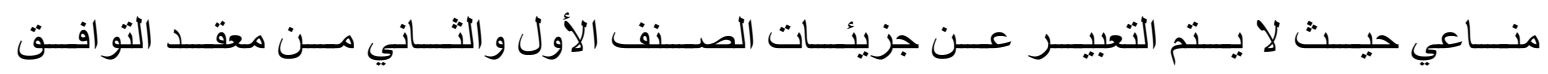

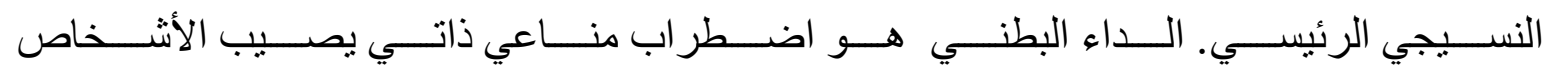

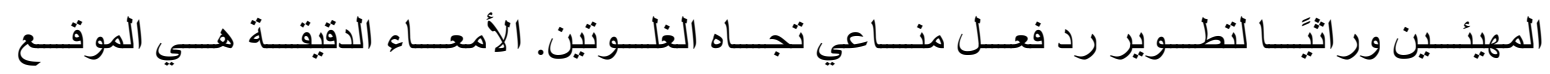

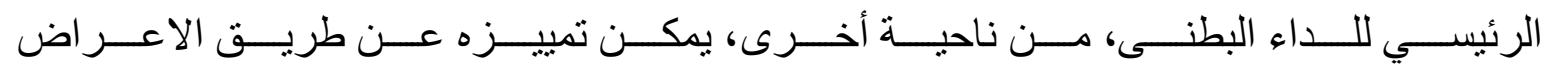

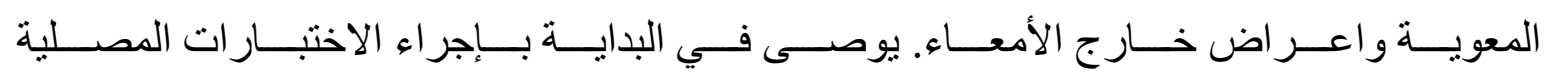

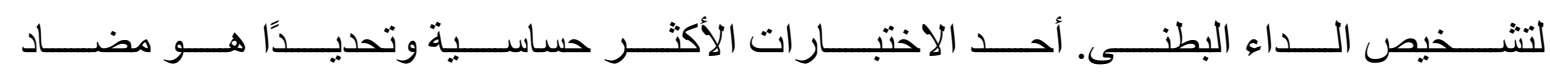

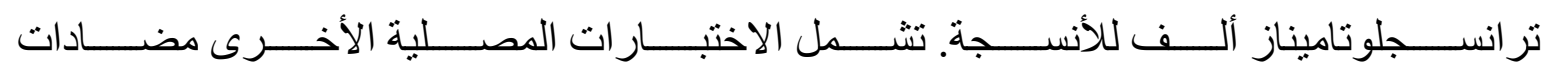
الغليادين ألف وجيم.

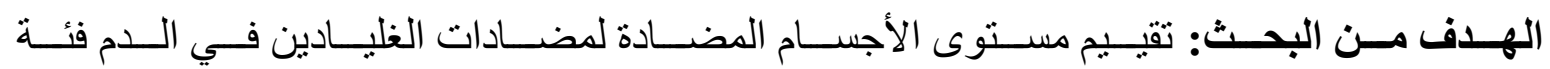
ألف وجيم في مرضي الثعلبة البقعية وعلاقتها بدرجة شدة المرض.

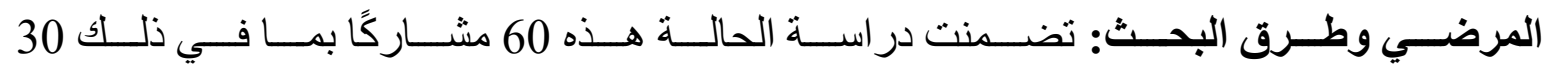

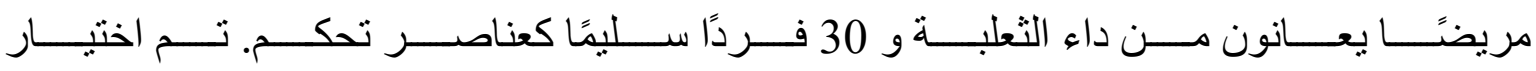

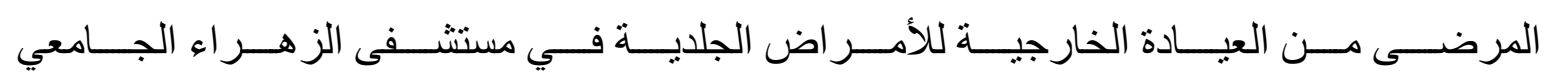
خلال الفترة من نوفمبر 2020 إلى أبريل 2021. 


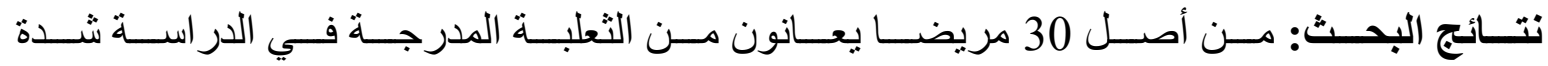

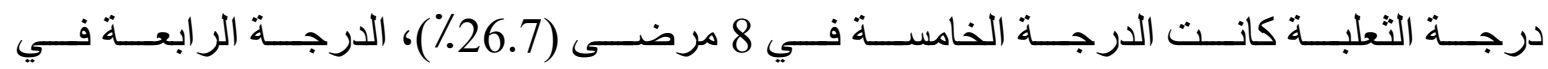

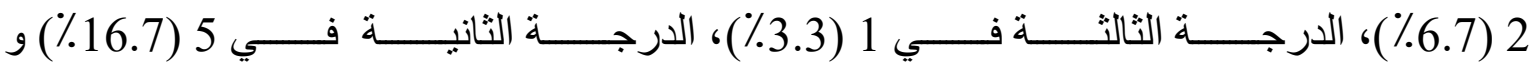

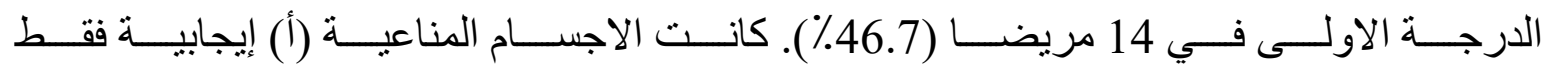

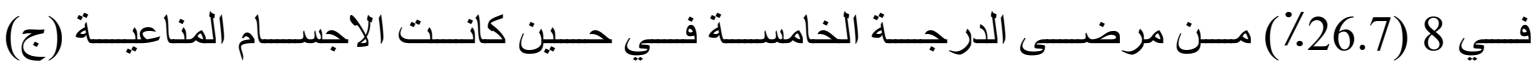

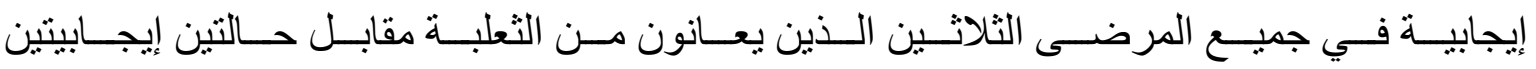

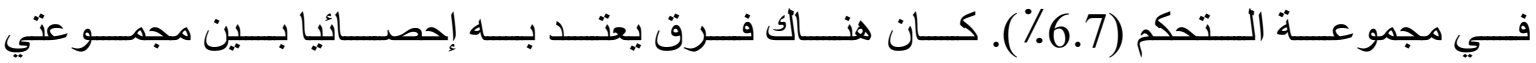

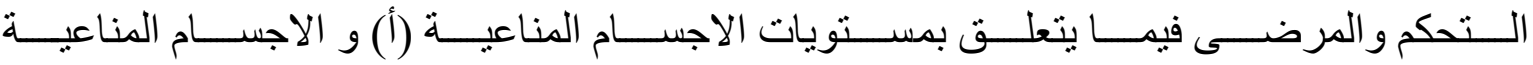

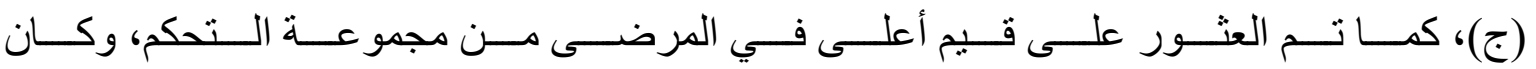

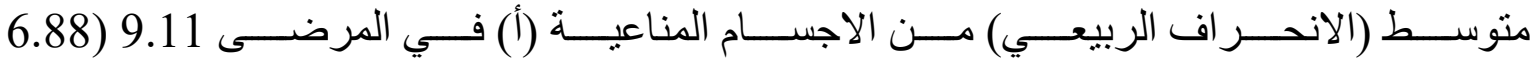

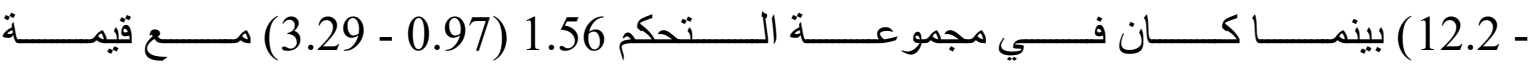

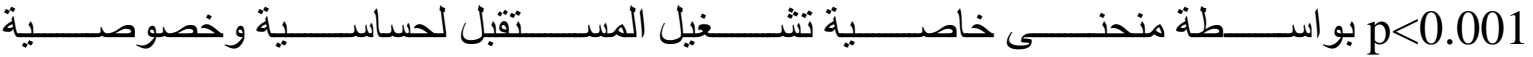

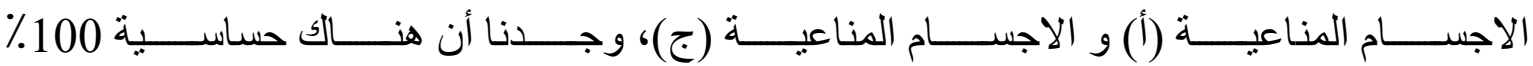

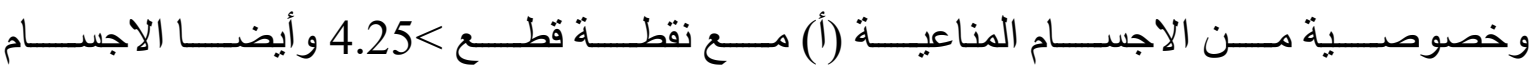
المناعبة (ج) مع نقطة قطع >13.

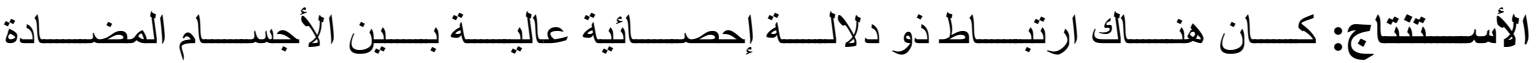

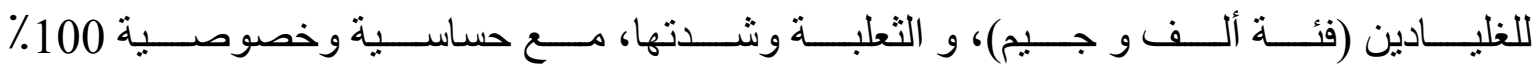

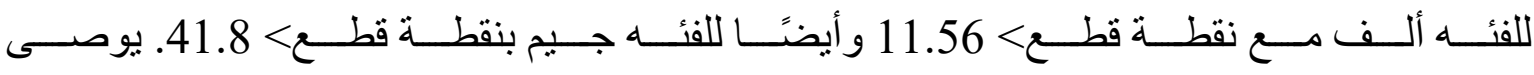

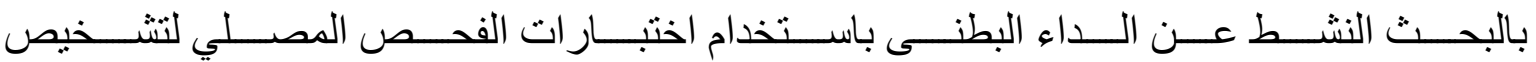
الحالات العديدة لمرضي الداء البطنى تحت الإكلينيكي في مرضى الثعلبة البقعية.

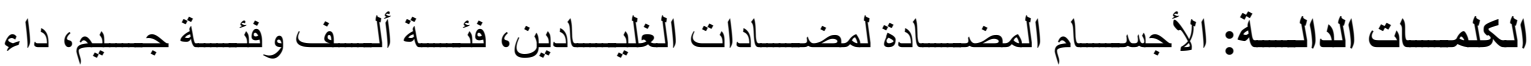

